\title{
Fabrication and characterization of PZT thin films for micromotors
}

\author{
Paul Muralt, Andrej Kholkin, Markus Kohli, \\ Thomas Maeder, Keith G. Brooks, Roland Luthier (a) \\ Laboratoire de Céramique, Ecole Polytechnique Fédérale de Lausanne, MX-D Ecublens, CH-1015 Lausanne, Switzerland. \\ (a) ASULAB, CH-2074 Marin-Epagnier, Switzerland.
}

Version of record: Integrated Ferroelectrics 11 (1-4), 213-220, 1995.

http://hdl.handle.net/10.1080/10584589508013593

\begin{abstract}
Piezoelectric membranes consisting of $\mathrm{PbZr}_{\mathrm{x}} \mathrm{Ti}_{1-\mathrm{x}} \mathrm{O}_{3}$ (PZT) films on silicon diaphragms have been fabricated, investigated, and applied for micromotors. The PZT films were deposited by sputtering and sol gel techniques. Resonance amplitudes of up to $1000 \mathrm{~nm} / \mathrm{V}$ have been measured for $16 \mu \mathrm{m}$ thick, $2 \mathrm{~mm}$ diameter membranes with $0.6 \mu \mathrm{m}$ PZT. The PZT films show a preferred direction of polarization, which seems to depend on the deposition technique. Membranes of $4 \mathrm{~mm}$ diameter have been successfully applied as a vibrator of a micro motor, allowing for the first time the characterization of a PZT thin film micro motor. The motor could be operated with voltages as low as $1.0 \mathrm{Vrms}$, which is much less than has been obtained with $\mathrm{ZnO}$ micro motors and is sufficiently low for standard battery and IC supply voltages. A $100 \mathrm{~h}$ degradation test of frequency and amplitude has revealed a $5 \%$ drop in amplitude, possibly due to depolarization.
\end{abstract}

\section{Introduction}

The miniaturization of ultrasonic motors is a subject of keen interest. This type of motor is considered to be superior to other types of micromotors for down scaling [1]. Such micromotors will allow further miniaturization accompanied by an increase in the functionality of micro robots, autofocusing lens systems, watches and precision positioning devices. The fabrication technology has to be adapted to the small dimensions. One possible approach is a so-called hybrid micromotor, where the stator consists of a piezoelectric thin film on a micro-machined silicon diaphragm. The rotor is fabricated by rather classical means and added in an assembly step. In the past three years the first piezoelectric thin film micromotors of this type have been demonstrated [2-5]. With regard to bulk material properties, $\mathrm{PbZr}_{\mathrm{x}} \mathrm{Ti}_{1-\mathrm{x}} \mathrm{O}_{3}(\mathrm{PZT})$ appears to be the best choice for the piezoelectric film. However, PZT thin film processing and integration issues complicate device fabrication. The high deposition or annealing temperatures of about $600^{\circ} \mathrm{C}$ are usually not compatible with other materials on the device and interdiffusion and/or delamination may occur. For this reason the first micromotors have either been fabricated with the much less effective piezoelectric $\mathrm{ZnO}[2,5]$, or, when PZT films have been applied, suffered a very fast degradation, preventing a characterization of the motor $[3,4]$.

In this work we report on the fabrication and characterization of a PZT actuated stator membrane and on the successful functional characterization of a micromotor built with this membrane. The motor is a hybrid type with an elastic fin rotor, proposed by Kurosawa et al. [6,7] for down scaling, and whose micromechanical version was first realized by Racine et al. [5] with $\mathrm{ZnO}$ thin films. As expected, PZT yielded a higher speed of the motor at a given voltage. In order to assure industrialization of PZT films, reliability issues have to be addressed, too. First results about yield, reproducibility, and deterioration are thus reported. 


\section{Fabrication}

The structure of the piezoelectric thin film stator was made as simple as possible and is shown schematically in Fig. 1. The electrode below the PZT film (bottom electrode of Pt/Ta) was not structured. Contact pads, conductor lines and top electrodes were patterned from the same aluminum film, deposited directly on the PZT layer. The additional capacity of the contact pads and the conductor lines amounts to $18 \%$ of the total capacity and was not considered to be important for the present investigation.

The stator was micro machined out of a 3" silicon wafer. The wafers have been purchased with thermal oxide and LPCVD-Si $\mathrm{N}_{4}$ layers. Their thicknesses have been matched for a small and slightly tensile resulting stress and serve as a mask for the silicon micro machining (etching in $\mathrm{KOH}$ ), and as a barrier layer against lead-silicon inter diffusion. The first processing step was the structuring of these two layers on the back side of the wafer for the later $\mathrm{KOH}$ etching. Next the bottom electrode $(100 \mathrm{~nm} \mathrm{Pt} / \mathrm{Ta})$ was sputter deposited on the front side. The selection of the right electrode material and process is crucial. We tested several adhesion layers between $\mathrm{Si}_{3} \mathrm{~N}_{4}$ and $\mathrm{Pt}$. Among $\mathrm{Ti}, \mathrm{TiO}_{2} / \mathrm{Ti}, \mathrm{Ta}, \mathrm{Ta}_{2} \mathrm{O}_{5} / \mathrm{Ta}$ the single $\mathrm{Ta}$ layer withstood best the annealing in oxygen at $600{ }^{\circ} \mathrm{C}$ and the subsequent patterning steps. This is in contrast to the optimal solution on the barrier layer $\mathrm{SiO}_{2}$, where the $\mathrm{TiO}_{2} / \mathrm{Ti}$ is by far the best choice among the above mentioned materials [8].

For the PZT deposition two methods have been applied: sol gel and sputtering. The processes needed minimal temperatures of $600^{\circ} \mathrm{C}$ (sol gel) and $550^{\circ} \mathrm{C}$ (sputtering). The sol gel process used the organometallic precursors $\mathrm{Pb}\left(\mathrm{C}_{2} \mathrm{H}_{4} \mathrm{O}_{2}\right)_{2} \cdot 3 \mathrm{H}_{2} \mathrm{O}, \mathrm{Zr}\left(\mathrm{OCH}_{2} \mathrm{CH}_{2} \mathrm{CH}_{3}\right)_{4}$ and $\mathrm{Ti}\left[\mathrm{OCH}\left(\mathrm{CH}_{3}\right)_{2}\right]_{4}$. The film exhibits a strong $<111>$ texture. Details have been previously reported $[9,10]$. The sputtered PZT with $<100>$ orientation was grown in situ from 3 simultaneously operating magnetrons with metal targets. The orientation was obtained due to a $<100>$ oriented lead titanate template layer of $30 \mathrm{~nm}$ thickness, which was deposited initially. A detailed description of the process is given in ref. [11]. In both cases the PZT film was $0.6 \mu \mathrm{m}$ thick, which was enough for the low voltage operation we aimed at.

The aluminum top electrode was deposited by evaporation and structured afterwards. Finally the silicon etching in $\mathrm{KOH}$ of the back side was performed, leaving membranes with 5 to $30 \mu \mathrm{m}$ thick silicon, depending on the etching time. Ten membranes were simultaneously etched on a quarter wafer. For motor operation the wafer was turned up-side down. The rotor was thus moving on the silicon side in the etched cavity.

Three sizes of membranes with diameters of 2, 4 and $8 \mathrm{~mm}$ have been fabricated. The top electrodes with half the diameter of the membrane allowed excitation of the ground mode B00 as well as the B10 mode with one circular node. The circular stator membranes applied for the motor had diameters of $4 \mathrm{~mm}$. The rotor axle was positioned by a centering wheel hold by gravity on the wafer. On the top of the axle a wheel was fixed which served as a load to increase the friction and the moment of inertia for torque measurements.

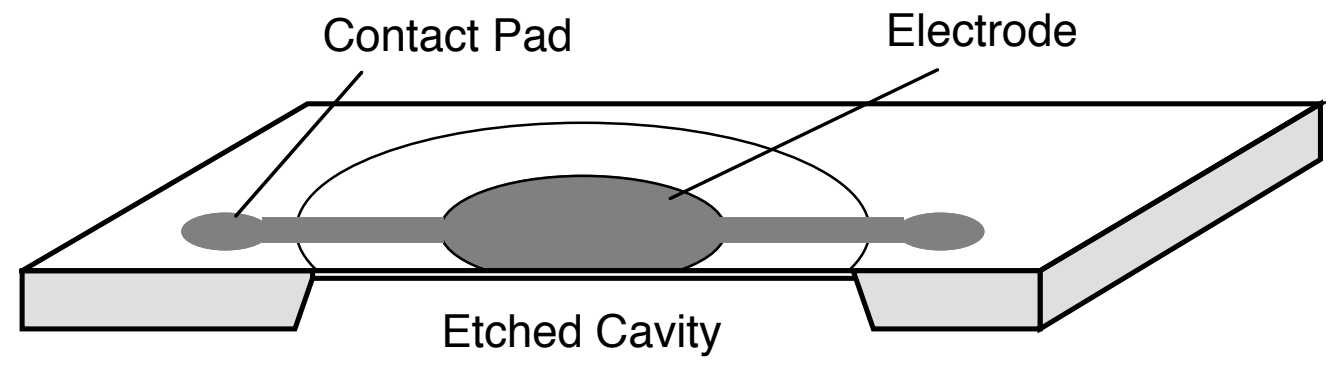

Figure 1. Schematic drawing of the membrane with view onto the top side of the wafer. 


\section{Characterization}

For the sputtered PZT film, the losses of all 10 stator capacitors on a quarter wafer have been measured. Apart from one, all values were close together (see Fig. 2) and reached the low values (3.5 to $5 \%$ ) of the $0.6 \mathrm{~mm}$ diameter electrodes at $100 \mathrm{~Hz}$. This proves that no pin-hole problem occurred during fabrication and that a high yield was obtained. The rise of the losses at higher frequencies was due to the large inductance of the measurement set-up, which, in combination with the large stator capacities $(35 \mathrm{nF})$, gave rise to a $\mathrm{LC}$ resonance below $1 \mathrm{MHz}$.

The membrane deflections as a function of the excitation frequency have been measured by means of optical interferometry (see Fig. 3). A resonance amplitude of up to $800 \mathrm{~nm} / \mathrm{V}$ has been found for the ground mode $\left(\mathrm{B}_{00}\right)$ at $26 \mathrm{kHz}$ with a $28 \mu \mathrm{m}$ thick, $4 \mathrm{~mm}$ wide membrane, covered with $0.6 \mu \mathrm{m}$ PZT. The symmetry of the modes has been determined by mapping the nodal lines with quartz powder (Chladni figures). The PZT films exhibit a preferred direction of polarisation, which seems to depend on the deposition process. Sol-gel films required a positive bias at the top electrode, sputtered films a negative one for poling in the preferred direction. The piezoelectric coupling can be increased by a dc field superimposed on the driving ac field. This is compatible with hysteris and $\mathrm{d}_{33}$ measurements of PZT thin films, which showed a polarization of only half of the saturated value at zero field $[12,13]$.

For not too small thicknesses, our membranes are in principle well approximated by the model for thin clamped circular disks, for which exact values of the resonance frequencies are available $[14,15]$. In the limit of zero thickness, pure membrane behavior should be observed. Also in this case the resonance frequencies can be calculated [14,15]. Being independent of (not precise) membrane thickness measurements, the frequency ratio $\mathrm{f}\left(\mathrm{B}_{10}\right) /\left(\mathrm{B}_{00}\right)$ was compared with the theory. The spectrum of the same 2 $\mathrm{mm}$ membrane was measured for different silicon thicknesses. The results shown in Fig. 4 show clearly the transition from membrane (theoretical ratio of 2.30) to disk behavior (theoretical ratio of 3.91). The small deviation from theoretical disk behavior suggests that the films on top of the silicon membranes have a low total stress.

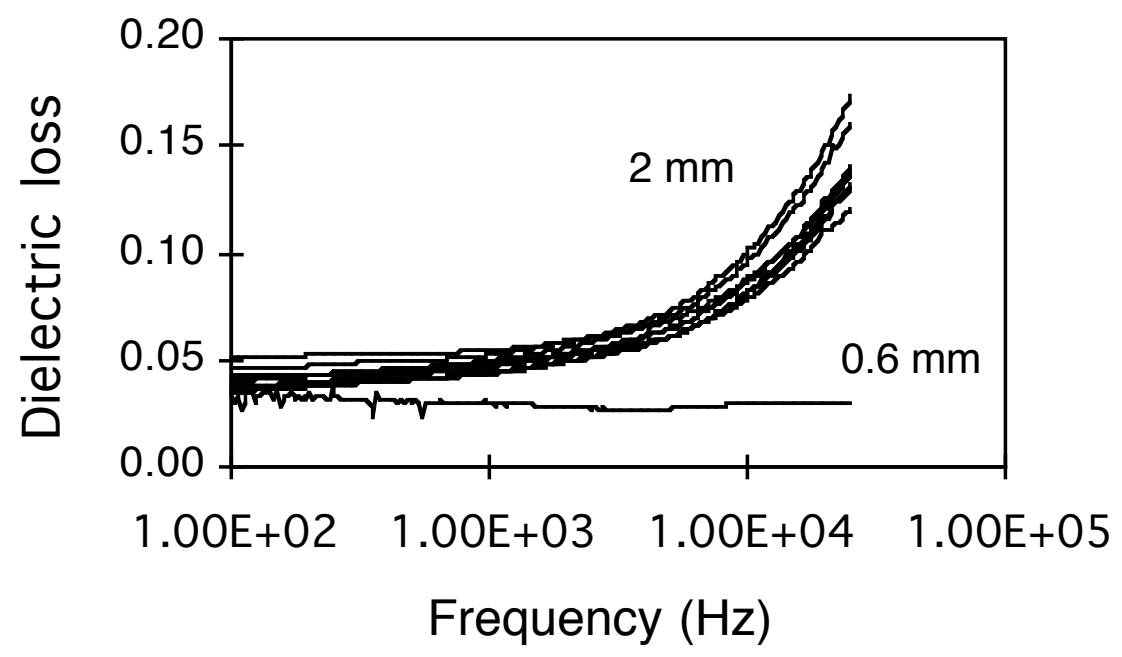

Figure 2. Scatter of dielectric loss vs. frequency for nine $2 \mathrm{~mm}$ capacitors on $20 \mu \mathrm{m}$ membranes, situated on the same quarter wafer. The rise of the losses at higher frequencies is explained in the text. The losses of a $0.6 \mathrm{~mm}$ diameter capacitor is shown for comparison. 


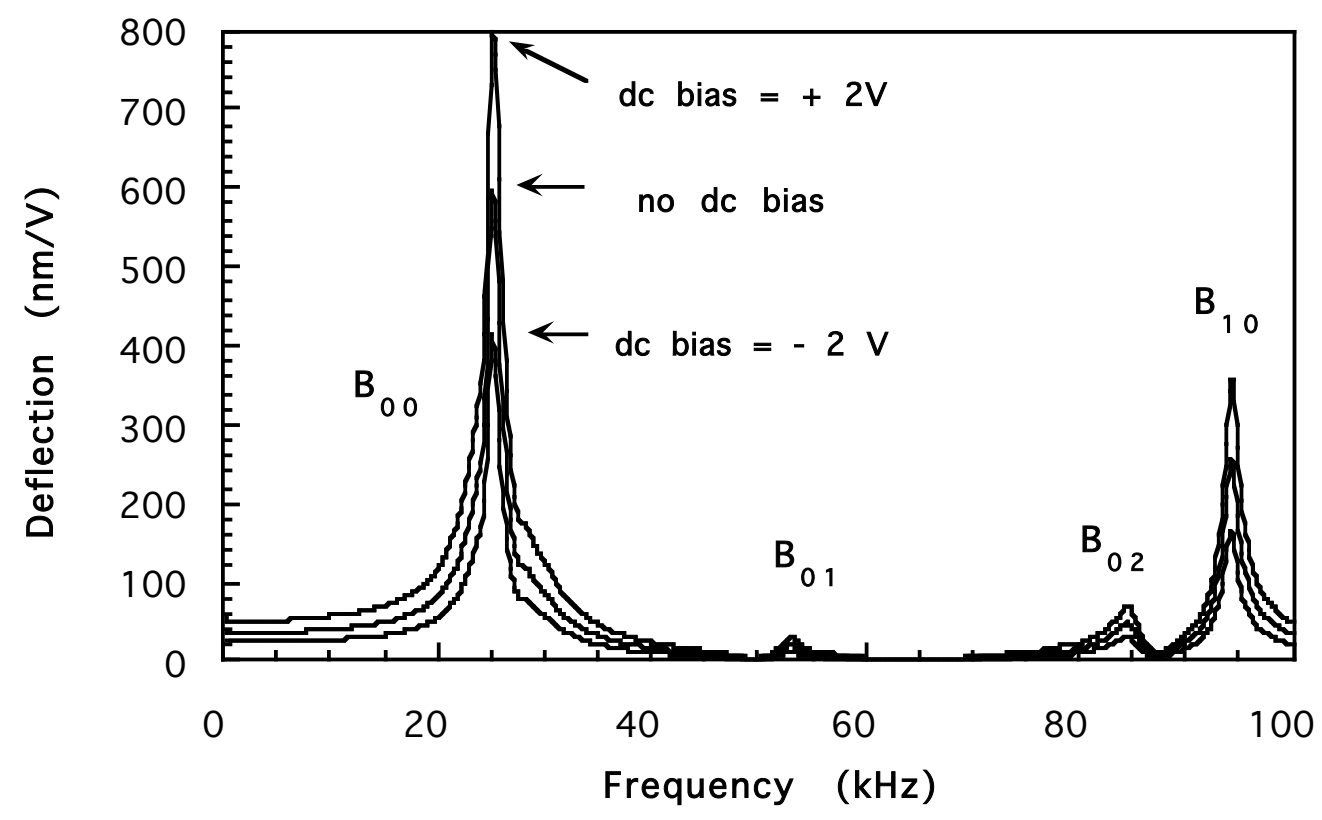

Figure 3. Deflection vs. excitation frequency of a $27 \mu \mathrm{m}$ thick membrane of $4 \mathrm{~mm}$ diameter with $0.6 \mu \mathrm{m}$ sol gel PZT for different dc bias voltages. Numbering of modes: first index for number of nodal circles, second one for number of nodal lines.

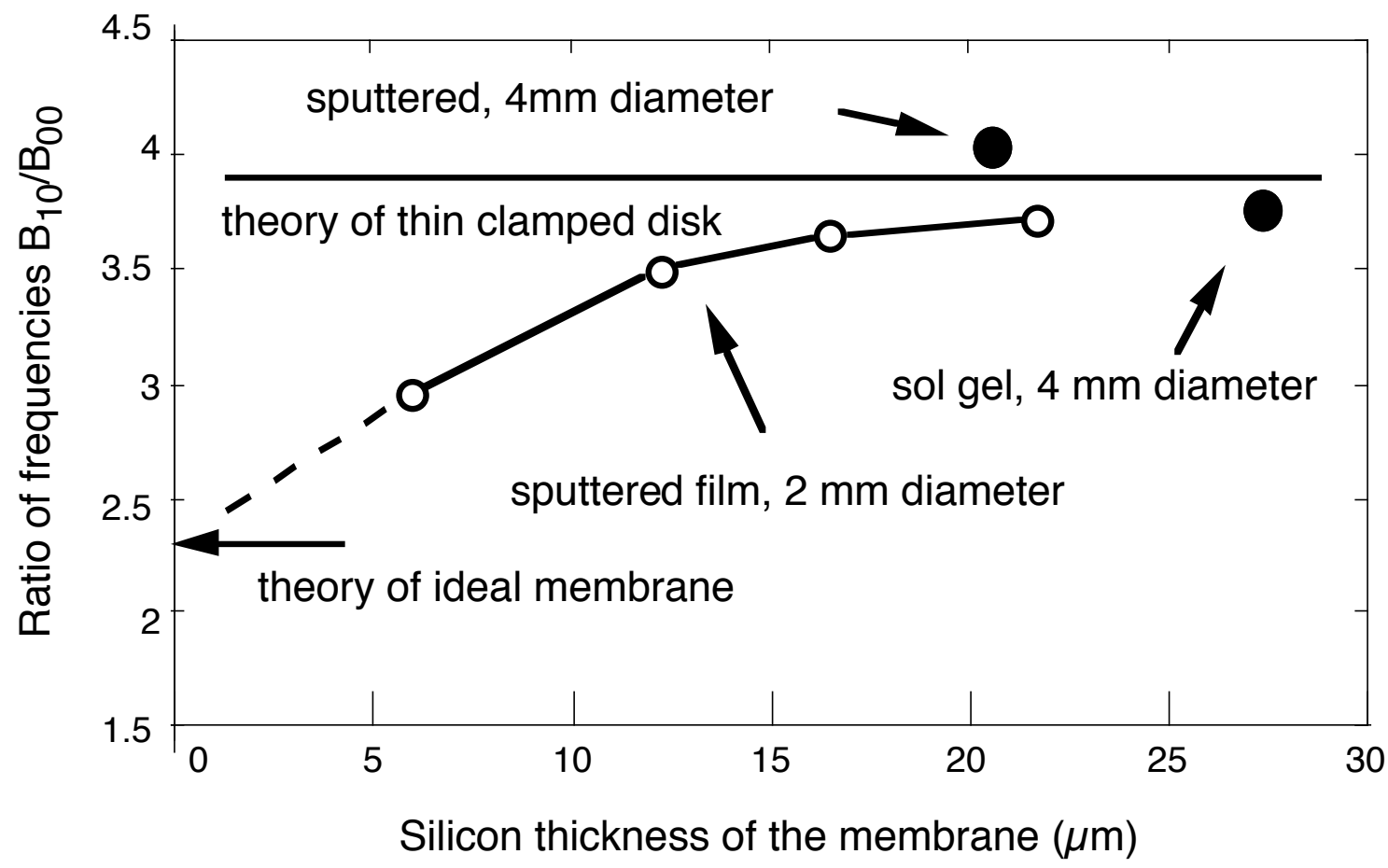

Figure 4. Frequency ratio of modes for comparison with theory. The broken line is expected behavior. 


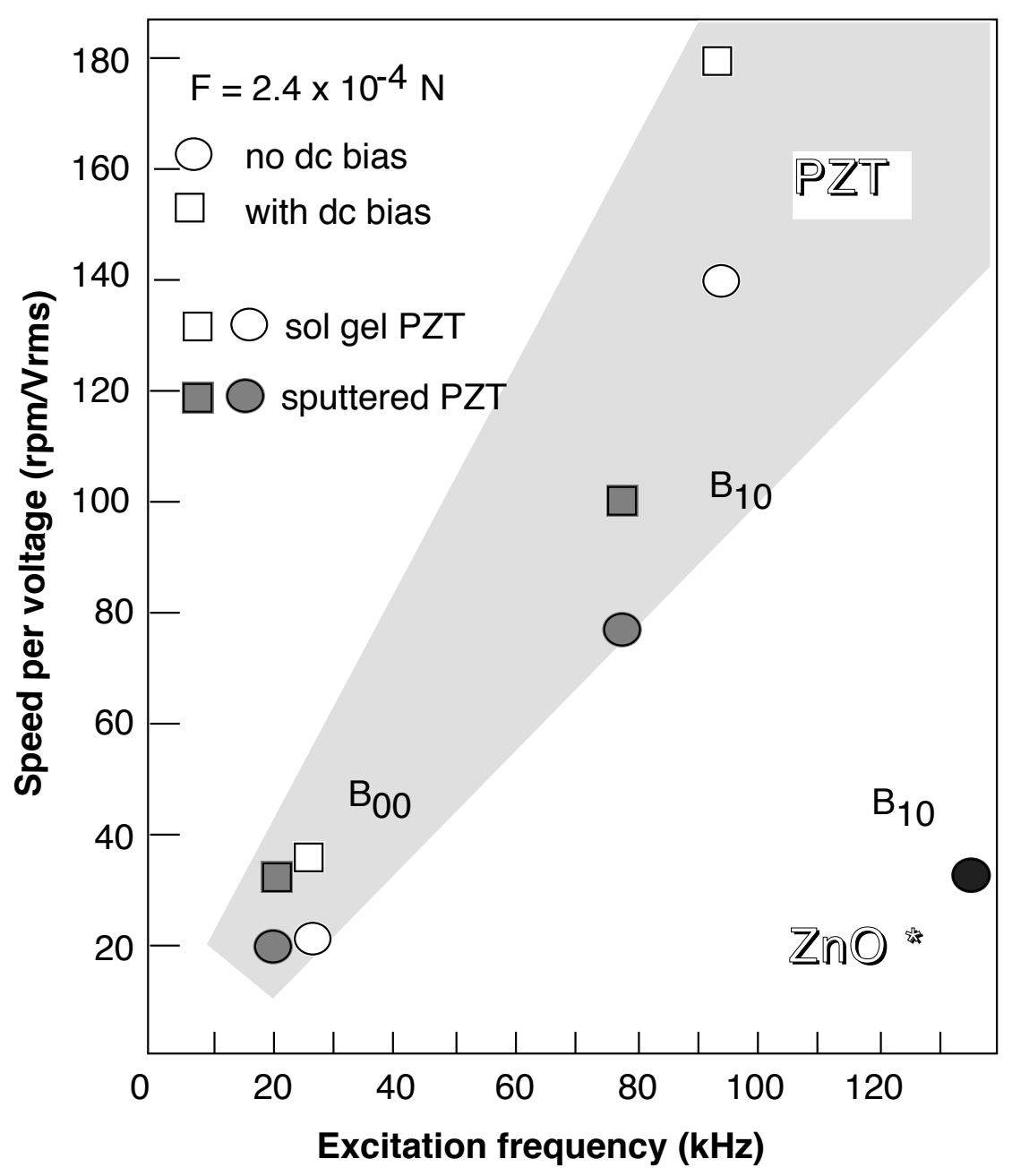

Figure 5. Summary of speed measurements operating the motor with the circular modes $B_{00}$ and $B_{10}$ at a small force $F$ between rotor and stator.

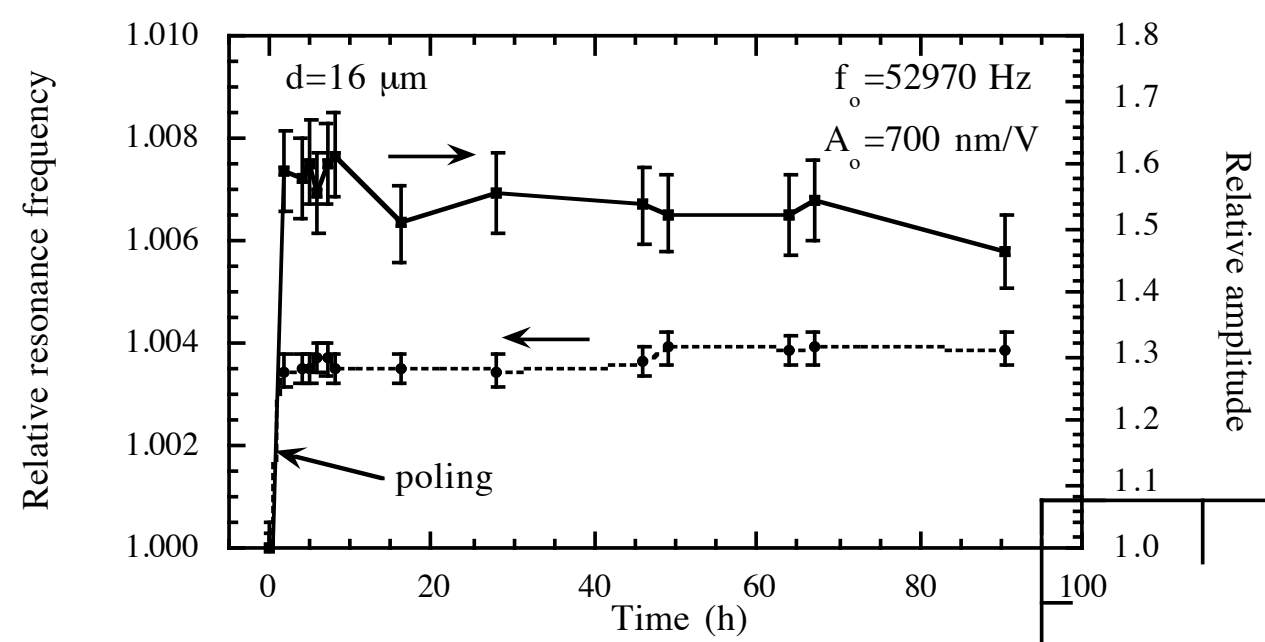

Figure 6. Frequency and amplitude of the ground mode vs. time during a long time test. The membrane was $2 \mathrm{~mm}$ in diameter, $16 \mu \mathrm{m}$ thick and covered with $0.6 \mu \mathrm{m}$ sputtered PZT. 
The $4 \mathrm{~mm}$ membranes have been successfully applied as a vibrator for an elastic fin micro motor. Speed and torque have been measured by means of video films for various operating conditions. The motor could be operated with voltages as low as $1.0 \mathrm{Vrms}$, which is much less than has been obtained with $\mathrm{ZnO}$ micro motors and is sufficiently low for standard battery and IC supply voltages. A torque of $35 \mathrm{nNm}$ was obtained with a force of $1 \mathrm{mN}$ between rotor and stator. A summary of speed measurements is given in fig. 5. The speed increases linearly with excitation frequency, which was predicted by simulation calculations and confirmed for the bulk PZT version [7].

A long term $(100 \mathrm{~h})$ test of motor operation yielded the surprising result that the speed slightly increased. This may have several reasons. The friction between stator and rotor could have changed in a favorable manner, or the piezoelectric coefficient increased. In order to avoid this ambiguity deflection measurements of an unloaded $2 \mathrm{~mm}$ membrane with a sputtered PZT film have been performed. The result is shown in fig. 6 . The first point is the virgin film. Self poling during the first hour occurred at the same operating conditions as applied during the whole test of $100 \mathrm{~h}$ (i.e. $2 \mathrm{~V}[-1+\sin (\omega \mathrm{t})]$ ). A dc bias was applied in order to work with one polarity only. Whereas the frequency stayed stable or increased slightly (about $0.06 \%$ ), the amplitude dropped by about $5 \%$. This might be attributed to depolarization. For each measurement the ac voltage was reduced to $1 \mathrm{mVrms}$ in order to stay within the deflection measurement range of the interferometer. This procedure probably influenced the poling of the film and reduced the reproducibility of the data (see error bars in Fig. 6)

\section{Conclusions}

The speed of PZT micromotors as compared to ZnO micromotors is 4 to 6 times higher, which roughly corresponds to the ratio of the piezoelectric $\mathrm{e}_{\mathrm{ij}}$ coefficients. High fabrication yields for integrated PZT films on silicon based mechanical devices is now possible. PZT activated membranes could be operated with a fairly good reliability and stability within the time frame investigated so far. Since anyhow a speed regulation is needed for precise operation of ultrasonic motors, the amplitude drift could be corrected by adjusting the dc or the ac voltage. The break down limits during long time operation have yet to be determined.

\section{Acknowledgements}

This work was supported by the Materials Priority Program of the Board of the Swiss Federal Institutes of Technology, the Swiss Federal Office of Education and Science (OFES), and the European COST 514 program. Mr. Jacques Castano is acknowledged for technical help.

\section{References}

[1] A.M. Flynn, L.S. Tavrow, S.F. Bart, R.A. Brooks, D.J. Ehrlich, K.R. Udayakumar, and L.E. Cross, Piezoelectric micromotors for microrobots, J. Microelectromechanical Systems, $\underline{1}$, 44-51 (1992).

[2] R.M. Moroney, R.M White, and R.T. Howe, Ultrasonic micromotors: physics and applications, Proc. IEEEMEMS, Napa Valley, USA, 1990, pp. 182-187.

[3] K.R. Udayakumar, S.F. Bart, A.M. Flynn, J. Chen, L.S. Tavrow, L.E. Cross, R.A. Brooks, and D.J. Ehrlich, Ferroelectric thin film ultrasonic micromotors, Proc. IEEE-MEMS, Nara, Japan, 1991, pp.109-113.

[4] 4.K.R. Udayakumar, J. Chen, A.M. Flynn, K.G. Brooks, L.E. Cross, and D.J. Ehrlich., Piezoelectric thin film ultrasonic micromotors, MRS Symposium Proceedings, 243, 49-54 (1992).

[5] G.-A. Racine, R. Luthier, and N.F. de Rooj, Hybrid ultrasonic micromachined motors, Proc. IEEE-MEMS, Fort Lauderdale, USA, 1993, pp. 128-132.

[6] T. Uchiki, T. Nakazawa, K. Nakamura, M. Kurosawa, and S. Ueha, Ultrasonic motor utilizing elastic fin rotor, Jap.J.Appl.Phys., 30, 2289-2291 (1991) .

[7] M. Kurosawa, T. Uchiki, H. Hanada, K. Nakamura, and S. Ueha, Simulation and experimental study on elastic fin ultrasonic motor, IEEE Ultrasonics Symposium, Tucson, USA, 1992, pp. 893-896.

[8] K. Sreenivas, I. Reaney, T. Maeder, N. Setter, C. Jagadish, and R. G. Elliman, Investigation of Pt/Ti bilayer metallization on silicon for ferroelectric thin film integration, J.Appl.Phys, 75, 232-239 (1994).

[9] K.G. Brooks, I.A. Reaney, R. Klissurska, Y. Huang, L. Bursill, and N. Setter, Orientation of rapid thermally annealed lead zirconate titanate thin films on (111) Pt substrates, J. Mater. Res., 9, 2540-2553 (1994). 
[10] I. M. Reaney, K.G. Brooks, R. Klissurska, Cz. Pawlaczyk, and N. Setter, Use of transmission electron microscopy for the characterisation of rapid thermally annealed sol-gel PZT films, J.Amer.Ceram.Soc.,77, 1209 - 1240 (1994) .

[11] T. Maeder and P. Muralt, In-situ thin film growth of $\mathrm{PbTiO}_{3}$ by multi target sputtering, MRS Symposium Proceedings, 341, 361-366 (1994).

[12] Jie-Fang Li, D.D. Viehland, T. Tani, C.D.E. Lakeman, and D.A. Payne, Piezoelectric properties of sol-gelderived ferroelectric and antiferroelectric thin layers, J. Appl. Phys., 75, 442-448 (1994).

[13] Q.M. Zhang, W.Y. Pan, and L.E.Cross, J.Appl.Phys. 63 (1988) 2492-2496.

[14] Istvan Szabo, Höhere Technische Mechanik, Springer, Berlin, 1956.

[15] S. Timoshenko, S. Woinowsky-Krieger, Theory of Plates and Shells, McGraw-Hill, New York, 1959. 